\title{
BMJ Open Neighbourhood socioeconomic status modifies the association between anxiety and depression during pregnancy and preterm birth: a Community-based Canadian cohort study
}

Kamala Adhikari (D) , ${ }^{1}$ Scott B Patten, ${ }^{1}$ Tyler Williamson, ${ }^{1}$ Alka B Patel, ${ }^{1,2}$ Shahirose Premji, ${ }^{3}$ Suzanne Tough, ${ }^{1,4}$ Nicole Letourneau, ${ }^{1,4,5,6}$ Gerald Giesbrecht, ${ }^{1,4}$ Amy Metcalfe ${ }^{1,7,8}$

To cite: Adhikari K, Patten SB, Williamson T, et al. Neighbourhood socioeconomic status modifies the association between anxiety and depression during pregnancy and preterm birth: a Community-based Canadian cohort study. BMJ Open 2020;10:e031035. doi:10.1136/ bmjopen-2019-031035

- Prepublication history and additional material for this paper are available online. To view these files, please visit the journal online (http://dx.doi. org/10.1136/bmjopen-2019031035).

Received 12 April 2019 Revised 28 December 2019 Accepted 07 January 2020

D) Check for updates

(c) Author(s) (or their employer(s)) 2020. Re-use permitted under CC BY-NC. No commercial re-use. See rights and permissions. Published by BMJ.

For numbered affiliations see end of article.

\section{Correspondence to} Dr Kamala Adhikari; kamala.adhikaridahal@ucalgary. ca

\section{ABSTRACT}

Objective This study examined the association of anxiety alone, depression alone and the presence of both anxiety and depression with preterm birth (PTB) and further examined whether neighbourhood socioeconomic status (SES) modified this association.

Design Cohort study using individual-level data from two community-based prospective pregnancy cohort studies (All Our Families; AOF) and Alberta Pregnancy Outcomes and Nutrition (APrON) and neighbourhood SES data from the 2011 Canadian census.

Setting Calgary, Alberta, Canada.

Participants Overall, 5538 pregnant women who were $<27$ weeks of gestation and $>15$ years old were enrolled in the cohort studies between 2008 and 2012. 3341 women participated in the AOF study and 2187 women participated in the APrON study, with 231 women participated in both studies. Women who participated in both studies were only counted once.

Primary and secondary outcome measures PTB was defined as delivery prior to 37 weeks of gestation. Depression was defined as an Edinburgh Postnatal Depression Scale (EPDS) score of $\geq 13$, anxiety was defined as an EPDS-anxiety subscale score of $\geq 6$, and the presence of both anxiety and depression was defined as meeting both anxiety and depression definitions.

Results Overall, $7.3 \%$ of women delivered preterm infants. The presence of both anxiety and depression, but neither of these conditions alone, was significantly associated with PTB (OR 1.6, 95\% $\mathrm{Cl} 1.1$ to 2.3) and had significant interaction with neighbourhood deprivation $(p=0.004)$. The predicted probability of PTB for women with both anxiety and depression was $10.0 \%$, which increased to $15.7 \%$ if they lived in the most deprived neighbourhoods and decreased to $1.4 \%$ if they lived in the least deprived neighbourhoods.

Conclusions Effects of anxiety and depression on risk of PTB differ depending on where women live. This understanding may guide the identification of women at increased risk for PTB and allocation of resources
Strengths and limitations of this study

- This study used data from two community-based prospective pregnancy cohort studies that were conducted in a relatively representative sample (compared to a hospital-based or clinic-based sample) of pregnant women.

- This study performed statistical analysis to examine the relationship between anxiety and depression during pregnancy and preterm birth by analysing the presence of both depressive and anxious symptoms versus isolated depressive or anxious symptoms as risk factors of preterm birth, and further analysing whether neighbourhood socioeconomic status modifies the relationship.

- This study analysed overall preterm birth as data on spontaneous and iatrogenic preterm birth were not available.

- The study sample over-represents women from urban areas of Alberta, with high socioeconomic status, thus limiting the generalisability of the findings to urban settings.

- The use of self-reported anxiety and depression measurement scales may introduce measurement inaccuracy.

for early identification and management of anxiety and depression.

\section{BACKGROUND}

Worldwide, a total of 15 million births occur preterm (ie, before 37 weeks of gestation), with a global average rate of $11.1 \%{ }^{1}$ Preterm birth (PTB) is responsible for $35 \%$ of neonatal deaths globally. ${ }^{2}$ Among survivors, it is also a significant risk factor for short and longterm morbidities, such as respiratory distress 
syndrome, cerebral palsy and learning difficulties. ${ }^{3-5}$ Despite substantial research and interventions to prevent PTB, the incidence of PTB has not declined and its aetiology remains unclear. ${ }^{16}$ Understanding the risk factors for PTB, such as psychosocial distress and neighbourhood low socioeconomic status (SES), may help identify women at increased risk, and assist in the allocation of resources, ultimately reducing the incidence of PTB.

PTB has been linked to psychosocial distress during pregnancy, specifically anxiety and depression-the most common mental health problems during pregnancy. ${ }^{7-10}$ However, the association between anxiety and depression during pregnancy and PTB is incompletely understood. Many previous studies on the association between anxiety and depression and PTB were conducted in medical settings (ie, hospital and clinic) with small samples and high rates of attrition. ${ }^{7910}$ Notably, most of the previous studies analysed anxiety or depression without considering that they may occur in a comorbid state. ${ }^{7-11}$ Comorbid anxiety and depression is, in fact, common (affecting up to $50 \%$ of women with anxiety or depression) and is more likely to involve severe symptoms of anxiety and depression than isolated anxiety or depression. ${ }^{12-14}$ Thus, comorbid anxiety and depression may pose a higher risk of PTB than isolated anxiety or depression, which may influence the association between anxiety or depression and PTB.

Anxiety and depression are negatively correlated with neighbourhood SES. ${ }^{15}$ Neighbourhood SES is an arealevel measure of SES, which aggregates individual SES (such as income, education and employment status) at a certain geographical level. ${ }^{16}$ Neighbourhood SES may influence the risk of PTB by exposing women to health benefiting or risk elevating factors, such as access to healthy foods, quality health services, opportunities for leisure activity and social support and exposure to societal stressors, crimes and poor air and water quality. ${ }^{16-19}$ Low neighbourhood SES may affect an individual's ability to fulfil daily needs, access resources, make lifestyle choices and cope with different situations. ${ }^{16-19}$ Thus, the risk of PTB that is associated with anxiety and/or depression during pregnancy may differ by neighbourhood SES. To our knowledge, this has not been examined.

This study examined the association of the presence of anxiety symptoms alone, depression symptoms alone and both anxiety and depression symptoms with PTB. This study further examined whether the presence of anxiety, depression and both anxiety and depression interact with neighbourhood SES to increase the risk of PTB. This may help to determine the subgroups of women who are at increased risk for PTB.

\section{METHODS}

\section{Data sources}

This study combined datasets from two communitybased prospective pregnancy cohort studies in Alberta, Canada $(\mathrm{n}=5528)$. The All Our Families (AOF) cohort study recruited 3341 pregnant women and the Alberta Pregnancy Outcomes and Nutrition (APrON) cohort study recruited 2187 pregnant women, with 231 women participating in both studies. Women contributed only one pregnancy in the cohort. Women who participated in both studies were only counted once. The description and comparability of these two cohort studies is available elsewhere, ${ }^{20}{ }^{21}$ and justifies combining these data sources. ${ }^{22}$ The AOF study aimed to examine maternal well-being and infant outcomes and the APrON study aimed to investigate the role of prenatal maternal nutrition on maternal mental health and infant outcomes. ${ }^{20} 21$ Briefly, each cohort study had similar inclusion criteria, sampling design (community-based, non-stratified sampling) and data collection methods. ${ }^{21}$ Both studies recruited pregnancy cohorts between 2008 and 2012 using community-based recruitment strategies (such as face-to-face recruitment in maternity clinics by research assistants or nurses and recruitment in public places using posters, pamphlets and brochures) and followed them up. The follow-up for mother and child dyad is still ongoing in both studies. ${ }^{21}$

We obtained two de-identified cohort datasets linked with neighbourhood SES data from SAGE (Secondary Analysis to Generate Evidence), the secure data repository developed by PolicyWise for Children \& Families which houses these datasets.

\section{Patient and public involvement}

This study used de-identified secondary data. Patient and public were not involved in the design or planning of the study.

\section{Variables}

Variables that were deemed similar in the two studies were harmonised and appended into a single new dataset. Women who participated in both studies $(n=231)$ were counted only once. Data on age, ethnicity (white includes all Caucasians and non-white includes all nonCaucasians), maternal SES, parity, body mass index (BMI), smoking status, social support, depression and anxiety were collected at $<27$ weeks of gestation (in the APrON study) and at $<25$ weeks of gestation (in the AOF study). BMI was calculated based on the self-reported pre-pregnancy height and weight (ie, immediately before pregnancy). Additionally, depression and anxiety were measured during the third trimester (APrON: 27-42 weeks of gestation; AOF: 34-36 weeks of gestation).$^{2021}$

Both cohorts used an identical measure of depression, that is, the Edinburgh Postnatal Depression Scale (EPDS). The EPDS is a 10-item self-reported scale with each item ranging from 0 to 3 to assess symptoms of current depression (ie, how women have felt in the past 7 days). ${ }^{23}$ The EPDS has high internal consistency of $0.87,{ }^{23}$ a sensitivity of $78 \%$ and specificity of $99 \%$ in the obstetric population, ${ }^{24}{ }^{25}$ and is the most common scale used to measure antenatal and postnatal depression. ${ }^{26}$ The recommended standard cut-off score of $\geq 13$ out of 30 points on the EPDS 
was used to define the presence of clinically significant depression during pregnancy. ${ }^{27}$ While the EPDS was specifically designed to assess depression, three items (namely items 3, 4 and 5) comprising the anxiety subscale (EDPS-3A) have been suggested as a measure of anxiety by previous studies ${ }^{28}{ }^{29}$ with a sensitivity of $66.7 \%$ and specificity of $88.2 \%$ in the obstetric population. ${ }^{29}$ The standard cut-off of $\geq 6$ out of a maximum of 9 is used to define the presence of clinically significant anxiety during pregnancy ${ }^{29}$ The cohort studies used different measures of anxiety: the AOF study used the State-Trait Anxiety Inventory and the APrON study used the Symptoms Checklist 90. Thus, the EDPS-3A was chosen as a measure of anxiety to have a consistent measure across studies and to avoid the introduction of misclassification bias related to the use of different tools. Presence of isolated anxiety or depression was defined as meeting the anxiety or depression definition during pregnancy. Presence of both anxiety and depression was defined as meeting both anxiety and depression definitions at the same time point in pregnancy. Births that occurred before 37 weeks of gestation were defined as PTB (both spontaneous and iatrogenic included). PTB was measured at 4 months of postpartum period based on maternal recall of week of gestation at delivery.

Neighbourhood SES data were measured by the Pampalon material deprivation index (derived from the 2011 Statistics Canada census $)^{30} 31$ which was aggregated at the dissemination area (DA) level. DA is the smallest geographical unit available in the Canadian census, consisting of 400-700 persons. ${ }^{32}$ The Pampalon material deprivation index is a composite measure of neighbourhood SES that combines the proportion of persons without high school diplomas, the average personal income and the rate of unemployment within the DA. It is used as a deprivation quintile, with quintile one representing the least deprived and quintile five representing the most deprived neighbourhoods. ${ }^{30}$ Neighbourhood SES was assigned to each cohort based on their postal code of residence at the time of cohort recruitment.

\section{Data analysis}

Bivariate analysis was used to identify variables associated with PTB as well as anxiety and/or depression ('anxiety only', 'depression only' and 'both anxiety and depression'). The significantly associated $(\mathrm{p}<0.05)$ variables were parity, ethnicity and BMI. A multivariable logistic regression model was constructed to examine the association between anxiety and/or depression and PTB. The model also included parity, ethnicity, BMI, maternal age, smoking, social support, maternal education and household total income variables. These variables were selected to adjust for in the model based on our prior knowledge (or conceptual understanding based on literature) that they are associated with both outcome (ie, PTB) and exposure (ie, anxiety and/or depression) but do not reside in the causal pathway of the relationship between anxiety and/or depression and PTB. The underlying hypothetical relationship of the variables have been shown using a direct acyclic diagram (online supplementary figure 1 ).

A multilevel multivariable logistic regression model, which assumes the lack of independence of observations and accounts for the variation between groups or areas, was then constructed to examine the effect modification of neighbourhood SES on the association between anxiety and/or depression and PTB. This model included interaction terms in addition to parity, ethnicity, BMI, maternal age, smoking, social support, maternal education and household total income variables. The interaction terms comprised 'anxiety only', 'depression only' and 'both anxiety and depression' combined with each quintile of deprivation indices. Deprivation quintile fourth and fifth were combined as there were few or no cases in some strata.

The presence of significant interactions was identified through the $\mathrm{p}$ values associated with beta coefficients of each interaction term. Subsequently, we constructed another model without the interaction terms. A likelihood ratio test was used to compare the goodness of model fit between those two nested models - with and without the interaction terms. Adjusted prediction of PTB (ie, predicted probability of PTB that was evaluated at the average value of covariates, parity, ethnicity, BMI, maternal age, smoking, social support, maternal education and household total income variables, across observations) was estimated using the model with interaction terms. Alpha $(\alpha)$ of $<0.05$ was used to determine statistical significance. All analyses were performed using STATA/ IC V.14.1.

\section{Missing data}

The proportion of missing data for gestational age at delivery (PTB) was $7.5 \%$, for neighbourhood deprivation indices was $7.8 \%$, and for BMI was $6.8 \%$. Other variables had missing data $<5 \%$, ranging from $1.3 \%$ for depression to $4.4 \%$ for household total income. The missing data for these variables occurred due to maternal non-response. Characteristics of groups of women (such as ethnicity, parity, BMI, neighbourhood SES, anxiety and depression) with and without missing data on PTB were compared to assess differences. Multiple imputation was used to address with missing data on the three variables (ie, PTB, BMI and neighbourhood deprivation indices) that had $\geq 5 \%$ missing data ${ }^{33}$ Using STATA's 'mi Package', the multiple imputation process was carried out in three steps as recommended by Rubin: imputation, analysis and combination. ${ }^{33}{ }^{34}$ The method assumes that the missing data are missing at random and attempts to estimate a missing value within a plausible set of values. ${ }^{33} 34$ The imputation values (ie, a predictive distribution based on observed data) were estimated using an imputation model (with imputation 50 times). ${ }^{33} 34$ The imputation model included the variables that were significant with missing data (ie, marital status, duration of stay in Canada, intended pregnancy, alcohol consumption) 
as well as those that were used in the analysis model (ie, PTB, ethnicity, parity, BMI, maternal age, smoking, social support maternal education, household total income, neighbourhood SES, anxiety and depression, and interaction terms). Sensitivity analysis was done to compare the estimates from the analyses based on multiple imputation and from the analysis restricted to complete case.

\section{RESULTS}

Of total 5297 pregnant women, $17.9 \%$ of women had anxiety and/or depression: $7.7 \%$ of women had both anxiety and depression, followed by $6.0 \%$ women had anxiety alone, and $4.2 \%$ women had depression alone. Women with both anxiety and depression had a higher rate of PTB $(10.6 \%)$ compared to those with isolated anxiety $(6.5 \%)$ or isolated depression $(8.2 \%)$ or without anxiety and depression $(6.9 \%)$. A higher proportion of women with a presence of both anxiety and depression (compared to those with anxiety or depression alone) were single, non-white, recent immigrants, had a low household income and were from the most deprived neighbourhoods $(\mathrm{p}<0.05)$ (table 1$)$. Mean scores of anxiety (mean $=6.6, \mathrm{SD}=0.4)$ and depression $($ mean $=16.2$, $\mathrm{SD}=0.1$ ) were higher among women with both conditions compared to those with anxiety alone (mean=6.1, $\mathrm{SD}=0.2$ ) or depression alone (mean=14.6, $\mathrm{SD}=0.1$ ). As shown in table 2, women who delivered preterm infants were more likely to be non-white, obese, primiparous and from the most deprived neighbourhoods. Variables such as maternal ethnicity, parity, BMI, neighbourhood SES, anxiety and depression were significantly associated with the presence of missing data on PTB.

The presence of both anxiety and depression (adjusted OR (aOR) $1.6,95 \%$ CI 1.1 to 2.3 ), but neither anxiety alone (aOR $0.8,95 \%$ CI 0.6 to 1.6 ) nor depression alone (aOR $1.3,95 \%$ CI to $0.8,2.5$ ), was significantly associated with PTB (table 3). Effect modification was observed between the presence of both anxiety and depression and neighbourhood SES ( $p=0.004)$. Compared with women without anxiety and depression, women with both anxiety and depression who lived in quintile three and more deprived neighbourhoods had significantly increased odds of experiencing a preterm delivery (quintile 4 and 5: aOR 2.2, $95 \%$ CI 1.3 to, 4.0). In contrast, compared with women without anxiety and depression, women with both anxiety and depression who lived in the least deprived neighbourhood were not at elevated odds of experiencing a preterm delivery (aOR $0.2,95 \%$ CI 0.1 to 1.5) (table 3). The OR estimates from the analyses based on multiple imputation and from the analysis restricted to complete cases were similar, with some confidence intervals being slightly narrower in the multiple imputation analysis.

As shown in table 4 , the predicted probability of PTB for women with a presence of both anxiety and depression was $10.0 \%$ (95\% CI $6.8 \%$ to $13.1 \%$ ). It increased to $15.7 \%$ (95\% CI $9.5 \%$ to $23.2 \%$ ) if they lived in the most deprived neighbourhoods-an increase of $57.1 \%$-and it decreased to $1.4 \%$ (95\% CI $0.1 \%$ to $4.2 \%$ ) if they lived in the least deprived neighbourhoods. The predicted probability of PTB for women with depression alone was $9.6 \%$ (95\% CI $5.2 \%$ to $14.1 \%$ ), which increased to $14.1 \%$ (95\% CI 2.7\% to $25.3 \%$ ) if they lived in the most deprived neighbourhoods. The predicted probability for women with anxiety alone and women with absence of anxiety and depression remained similar across the neighbourhood deprivation indices.

\section{DISCUSSION \\ Main findings}

This study examined the association of anxiety alone, depression alone and the presence of both anxiety and depression during pregnancy with $\mathrm{PTB}$, using data from two community-based pregnancy cohort studies in Alberta, Canada. The study found an association between the presence of both anxiety and depression and PTB which significantly differed according to neighbourhood SES. Women with both anxiety and depression were more likely to deliver preterm infants if they lived in a relatively more deprived neighbourhood compared to if they lived in a less deprived neighbourhood. For women with both anxiety and depression, the absolute predicted probability of delivering preterm infants was $16 \%$ if these women lived in the most deprived neighbourhood, and it was $1 \%$ if they lived in the least deprived neighbourhood. Overall, the findings suggest the importance of neighbourhoods on maternal health (in general) and more specifically PTB.

\section{Interpretation}

Although few previous studies assessed the association between the presence of both anxiety and depression during pregnancy and PTB, our finding is consistent with their findings that the presence of both anxiety and depression increases the likelihood of PTB. ${ }^{14} 3536$ This may be related to the additive effects of prenatal depression and anxiety and the effects of severity of anxiety and depressive symptoms. Previous studies conducted in the general population and in pregnant women found a higher score of anxiety or depression symptoms among those with both anxiety and depression than those with isolated anxiety or depression. ${ }^{36}{ }^{37}$ It is also reported in previous studies that individuals with both anxiety and depression have longer depressive episodes, worse psychosocial impairment, poorer response to medication, compromised quality of life and increased suicidality than those with isolated anxiety or depression. ${ }^{12} 3537$ Thus, the presence of both anxiety and depression during pregnancy may lead to an increased risk of poor birth outcomes, including PTB, relative to depression or anxiety alone.

Our study did not find an association between anxiety alone or depression alone and PTB, which is consistent with a previous pregnancy cohort study that analysed isolated anxiety or depression separately from the 
Table 1 Distribution of maternal characteristics across anxiety and depression status during pregnancy

\begin{tabular}{|c|c|c|c|c|c|c|}
\hline \multirow{2}{*}{ Maternal characteristics } & Overall & $\begin{array}{l}\text { Absence of both } \\
\text { anxiety and } \\
\text { depression }\end{array}$ & $\begin{array}{l}\text { Presence of } \\
\text { anxiety only } \\
\end{array}$ & $\begin{array}{l}\text { Presence of } \\
\text { depression } \\
\text { only }\end{array}$ & $\begin{array}{l}\text { Presence of } \\
\text { both anxiety and } \\
\text { depression }\end{array}$ & \multirow{2}{*}{$\begin{array}{l}x^{2} \\
\mathbf{p} \text { value }\end{array}$} \\
\hline & $(n=5297)$ & $\mathrm{n}=4294(82.1 \%)$ & $\mathrm{n}=312(6.0 \%)$ & $\mathrm{n}=220(4.2 \%)$ & $\mathrm{n}=402(7.7 \%)$ & \\
\hline Maternal age & & & & & & 0.006 \\
\hline$<35$ years & $4117(79.2)$ & $3333(79.0)$ & $261(84.5)$ & $156(72.6)$ & $315((81.6)$ & \\
\hline \multicolumn{7}{|l|}{ Marital status } \\
\hline Single/divorced/separated & $262(5.1)$ & $168(3.9)$ & $22(7.2)$ & $25(11.5)$ & $47(11.8)$ & $<0.0001$ \\
\hline Married/common-law & $4916(94.9)$ & $4080(96.1)$ & $284(92.8)$ & $193(88.5)$ & $351(88.2)$ & \\
\hline Ethnicity & & & & & & $<0.0001$ \\
\hline Non-white & $1087(21.0)$ & 807 (19.0) & $68(22.2)$ & $67(30.9)$ & $143(36.1)$ & \\
\hline$<5$ years & $4636(90.7)$ & $352(8.4)$ & $31(10.1)$ & $27(12.7)$ & $61(15.6)$ & \\
\hline Body mass index & & & & & & 0.002 \\
\hline Underweight $\left(<18.5 \mathrm{~kg} / \mathrm{m}^{2}\right)$ & $214(4.3)$ & $170(4.2)$ & $12(4.1)$ & $11(5.3)$ & $21(5.6)$ & \\
\hline Normal weight $\left(18.5-24.99 \mathrm{~kg} / \mathrm{m}^{2}\right)$ & $3084(62.5)$ & 2552 (63.2) & $172(58.5)$ & $125(59.8)$ & $220(58.4)$ & \\
\hline Overweight $\left(25-29.99 \mathrm{~kg} / \mathrm{m}^{2}\right)$ & $1066(21.6)$ & $882(21.9)$ & $59(20.1)$ & $50(23.9)$ & $73(19.4)$ & \\
\hline Obesity $\left(\geq 30 \mathrm{~kg} / \mathrm{m}^{2}\right)$ & $574(11.6)$ & $432(10.7)$ & $51(17.4)$ & $23(11.0)$ & $63(16.7)$ & \\
\hline Parity & & & & & & $<0.0001$ \\
\hline Primiparous & 2649 (51.3) & $2135(50.3)$ & $199(64.6)$ & $106(48.8)$ & $205(51.9)$ & \\
\hline Multiparous & $2518(48.7)$ & $2106(49.7)$ & $109(35.4)$ & $111(51.2)$ & $190(48.1)$ & \\
\hline Some postsecondary & $859(16.7)$ & $669(15.8)$ & $57(18.9)$ & $35(16.2)$ & $96(24.4)$ & \\
\hline Completed postsecondary & $3688(71.5)$ & $3121(73.6)$ & $196(64.9)$ & $139(64.4)$ & $229(58.3)$ & \\
\hline Household income & $477(9.4)$ & & & & & $<0.0001$ \\
\hline$<\$ 40000$ & $723(14.3)$ & $325(7.8)$ & $25(8.4)$ & $40(18.6)$ & $85(22.0)$ & \\
\hline$\$ 40000-<\$ 70000$ & $1204(23.8)$ & $542(13.0)$ & $53(17.8)$ & $43(20.0)$ & $83(21.5)$ & \\
\hline$\$ 70000-<\$ 100000$ & 2659 (52.5) & $989(23.8)$ & $76(25.5)$ & $52(24.2)$ & $85(22.0)$ & \\
\hline$\geq \$ 100000$ & & $2301(55.4)$ & $144(48.3)$ & $80(37.2)$ & $133(34.5)$ & \\
\hline $\begin{array}{l}\text { Inadequate social support anytime during } \\
\text { pregnancy }\end{array}$ & $1148(22.1)$ & $731(17.1)$ & $77(25.0)$ & $127(57.4)$ & $210(52.4)$ & $<0.0001$ \\
\hline Neighbourhood deprivation index & & & & & & $<0.0001$ \\
\hline Quintile 1 (least deprived) & $1323(27.1)$ & $1108(27.7)$ & $68(24.3)$ & $51(24.9)$ & $80(22.4)$ & \\
\hline Quintile 2 & $1259(25.8)$ & $1045(26.1)$ & $82(29.3)$ & $41(20.0)$ & $83(23.2)$ & \\
\hline Quintile 3 & 972 (19.9) & $800(20.0)$ & $64(22.9)$ & $39(19.0)$ & $65(18.2)$ & \\
\hline Quintile 4 & $736(15.1)$ & $618(15.5$ & $37(13.2)$ & $30(14.6)$ & $47(13.1)$ & \\
\hline Quintile 5 (most deprived) & 595 (12.2) & $429(10.7)$ & $29(10.4)$ & $44(21.5)$ & $83(23.2)$ & \\
\hline Preterm birth & $356(7.3)$ & $276(6.9)$ & $19(6.5)$ & $16(8.2)$ & $37(10.6)$ & 0.068 \\
\hline
\end{tabular}

Sample size between variables differs as missing values were deleted using variable-wise or pair-wise deletion approach. 
Table 2 Distribution of maternal characteristics across preterm birth status

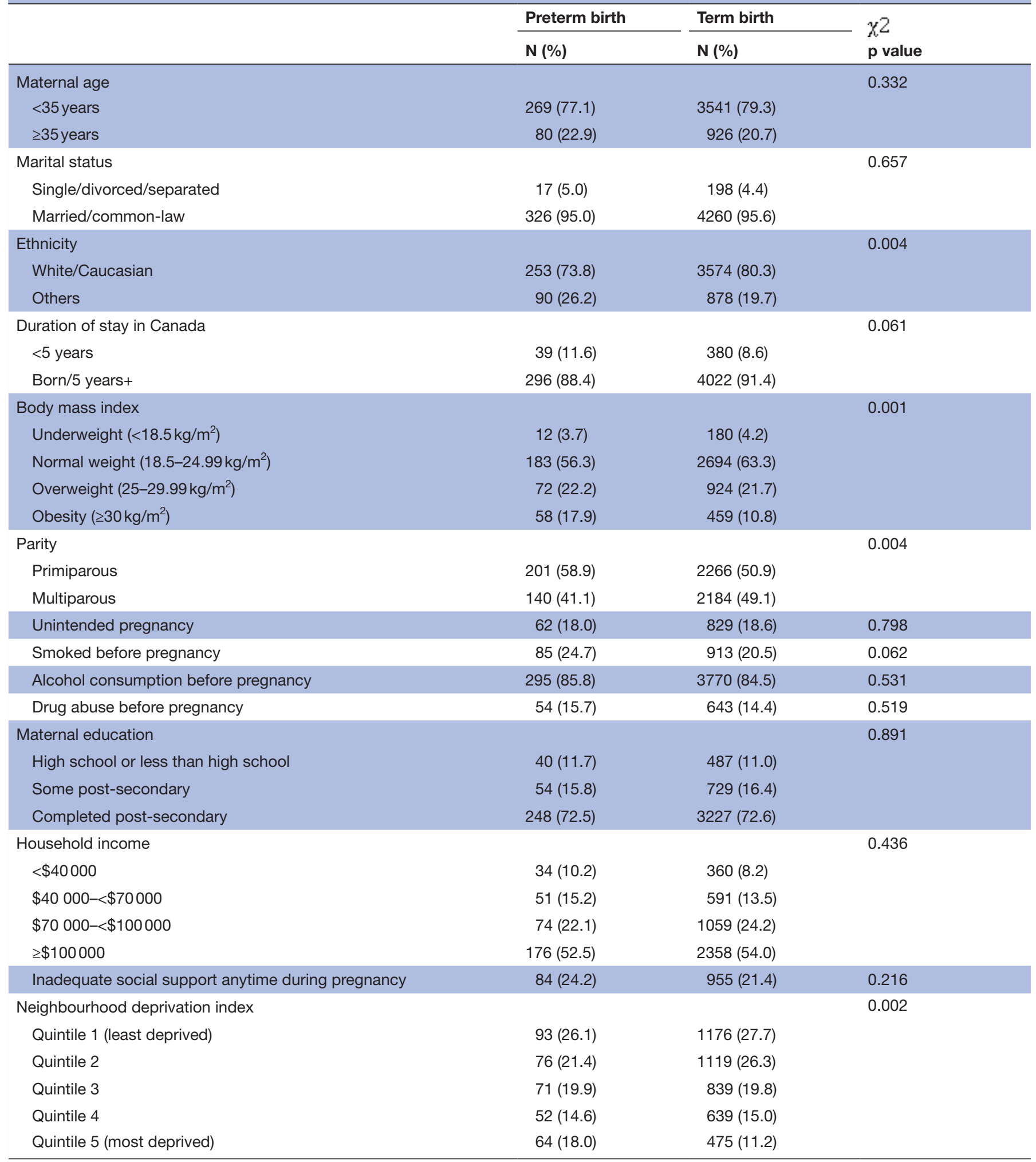

Sample size between variables differs as missing values were deleted using variable wise or pair wise deletion approach.

presence of both or comorbid anxiety and depression. ${ }^{36}$ However, the finding is inconsistent with several previous studies that analysed anxiety or depression intermixing with the presence of both conditions. ${ }^{810}$ It is possible that the association described in the literature requires high levels of anxiety or depression, which is more likely present in the presence of both anxiety and depression symptoms or disorders. Thus, the associations found in previous studies may have been confounded by the presence of both anxiety and depression symptoms or comorbid 
Table 3 Association between anxiety and depression status during pregnancy and preterm birth*

Stratified by neighbourhood deprivation indices (quintile)

\begin{tabular}{|c|c|c|c|c|c|}
\hline $\begin{array}{l}\text { Anxiety and depression status } \\
\text { during pregnancyt }\end{array}$ & $\begin{array}{l}\text { Overall } \\
\text { OR }(95 \% \mathrm{Cl})\end{array}$ & $\begin{array}{l}\text { Quintile } 1 \ddagger \\
\text { OR }(95 \% \mathrm{CI})\end{array}$ & $\begin{array}{l}\text { Quintile } 2 \\
\text { OR (95\% Cl) }\end{array}$ & $\begin{array}{l}\text { Quintile } 3 \\
\text { OR }(95 \% \mathrm{Cl})\end{array}$ & $\begin{array}{l}\text { Quintile } 4 \text { and } \\
5 \S \\
\text { OR }(95 \% \mathrm{Cl})\end{array}$ \\
\hline \multicolumn{6}{|l|}{ Unadjusted: } \\
\hline Presence of anxiety only & $0.9(0.6$ to 1.5$)$ & 0.8 (0.3 to 2.2$)$ & 0.8 (0.3 to 2.2$)$ & 1.1 (0.4 to 2.9$)$ & 1.3 (0.5 to 2.9$)$ \\
\hline Presence of depression only & $1.2(0.7$ to 2.1$)$ & $0.6(0.2$ to 2.1$)$ & 0.8 (0.2 to 3.6$)$ & 1.9 (0.7 to 4.2$)$ & 2.6 (0.9 to 6.1$)$ \\
\hline $\begin{array}{l}\text { Presence of both anxiety and } \\
\text { depression }\end{array}$ & 1.6 (1.1 to 2.3$)$ & $0.2(0.1$ to 1.5$)$ & $1.3(0.5$ to 3.1$)$ & 2.8 (1.3 to 5.5$)$ & 2.5 (1.3 to 3.7$)$ \\
\hline \multicolumn{6}{|c|}{$\begin{array}{l}\text { Adjusted for parity, ethnicity, body mass index, maternal age, smoking, social support, maternal education and household total } \\
\text { income: }\end{array}$} \\
\hline Presence of anxiety only & 0.8 (0.6 to 1.6$)$ & $0.7(0.2$ to 1.9$)$ & 0.7 (0.2 to 2.1$)$ & $1.0(0.4$ to 2.9$)$ & $1.0(0.4$ to 2.6$)$ \\
\hline Presence of depression only & 1.3 (0.8 to 2.5$)$ & 0.7 (0.2 to 2.5$)$ & $0.9(0.2$ to 4.1$)$ & 1.7 (0.8 to 4.7$)$ & 2.1 (0.9 to 7.0$)$ \\
\hline $\begin{array}{l}\text { Presence of both anxiety and } \\
\text { depression }\end{array}$ & $1.6(1.1$ to 2.3$)$ & $0.2(0.1$ to 1.5$)$ & 1.4 (0.6 to 3.3$)$ & 2.1 (1.2 to 5.8$)$ & $2.2(1.3$ to 4.0$)$ \\
\hline
\end{tabular}

*Estimates were from analyses based on multiple imputation.

†Absence of both anxiety and depression as a reference group.

$\ddagger$ Quintile 1: least deprived neighbourhood.

§Quintile 5: most deprived neighbourhood (quintiles 4 and 5 were combined due to few or no cases in some strata).

anxiety and depression disorders. The increased risk of PTB associated with the presence of both anxiety and depression (but not with isolated anxiety or depression) may, in part, explain the inconsistencies across previous findings on the association between prenatal anxiety or depression and PTB. Similarly, previous studies did not analyse the association stratified by neighbourhood SES, meaning that these studies averaged the association across neighbourhood SES, which may also explain the inconsistencies across previous studies findings.

A strong association between the presence of both anxiety and depression and PTB among women living in a relatively more deprived neighbourhood may reflect that, besides individual level risk factors, PTB is related to neighbourhood factors. ${ }^{16-18}$ For example, women living in deprived neighbourhoods often have less access to healthy foods, quality health services and opportunities for leisure activity, and have more exposure to societal stressors and crimes. ${ }^{16-19}$ Anxious and depressed women living in less advantaged areas may interpret the deprivation associated stressors more acutely and have less support or are less able to manage or cope with their stressors, making them severely emotionally distressed compared to those living in more advantaged areas. ${ }^{8113839}$ Consequently, the elevated risk of delivering preterm is more likely to occur in this group of women. However, it is important to note that, the relationship between mental illness and impoverishment is difficult to interpret as causal, given the bi-directional relationship between them. Furthermore, in our study, the group of women with both anxiety and

Table 4 Predicted marginal prevalence of preterm birth*

\section{Stratified by neighbourhood deprivation indices (quintile)}

\begin{tabular}{|c|c|c|c|c|c|}
\hline $\begin{array}{l}\text { Anxiety and depression } \\
\text { status during pregnancy } \dagger\end{array}$ & $\begin{array}{l}\text { Overall } \\
\%(95 \% \mathrm{Cl})\end{array}$ & $\begin{array}{l}\text { Quintile 1† } \\
\%(95 \% \mathrm{Cl})\end{array}$ & $\begin{array}{l}\text { Quintile } 2 \\
\%(95 \% \mathrm{Cl})\end{array}$ & $\begin{array}{l}\text { Quintile } 3 \\
\%(95 \% \mathrm{Cl})\end{array}$ & $\begin{array}{l}\text { Quintiles } 4 \text { and } \\
5 \ddagger \\
\%(95 \% \mathrm{Cl})\end{array}$ \\
\hline $\begin{array}{l}\text { Absence of both anxiety and } \\
\text { depression }\end{array}$ & $7.1(6.8$ to 13.1$)$ & 7.6 (5.6 to 9.3$)$ & 6.4 (4.8 to 7.9$)$ & 6.9 (5.1 to 8.8$)$ & 7.6 (5.9 to 9.3 ) \\
\hline Presence of anxiety only & 6.3 (3.3 to 9.1$)$ & $5.4(0.2$ to 10.7$)$ & $4.9(0.3$ to 9.5$)$ & 6.5 (0.3 to 12.7) & 7.9 (1.3 to 14.9$)$ \\
\hline Presence of depression only & 9.6 (5.2 to 14.1$)$ & $4.7(0.5$ to 10.4$)$ & $5.7(0.45$ to 13.4$)$ & 13.3 (3.0 to 23.2$)$ & $14.1(2.7$ to 25.3$)$ \\
\hline
\end{tabular}

*Adjusted for parity, ethnicity and body mass index, maternal age, smoking, social support, maternal education and household total income. †Quintile 1: least deprived neighbourhood.

$\ddagger$ Quintile 5: most deprived neighbourhood (quintiles 4 and 5 were combined due to few or no cases in some strata). 
depression (who often have severe symptoms of anxiety or depression) in the least deprived neighbourhoods had an exceptionally low rate of PTB. The observed association between the presence of both anxiety and depression and PTB among women living in a relatively more deprived neighbourhood seems to depend on this result. Thus, the replication of this finding seems important.

\section{Strengths and limitations}

To our knowledge, few studies have directly examined the presence of both depressive and anxious symptoms versus isolated depressive or anxious symptoms as risk factors of PTB, and no studies have examined neighbourhood SES as a modifier to the relationship between anxiety and/ or depression and PTB. This study is important given its focus on the most common psychological condition (ie, comorbid anxiety and depression) and the importance of identification of specific groups of women who may benefit the most from the preventive interventions. This study used two community-based prospective pregnancy cohort studies. This provided an opportunity to describe PTB across the several strata of anxiety, depression and both anxiety and depression and neighbourhood SES in a relatively representative sample (compared, for example, to a hospital-based or clinic-based sample) of pregnant women. However, even using the two cohorts, some strata had few cases of preterm infants, which may have led to the observed imprecise and/or insignificant estimates (specifically in a group with depression alone). As these cohorts over-represent women with high SES, ${ }^{21} 4041$ it limits the generalisability of the findings to other demographic groups. While the use of prospective measurement of depression and anxiety reduces the chance of misclassifications due to recall bias, the use of self-reported anxiety and depression measurement scales may have introduced measurement inaccuracy. Specifically, the EPDS-3A scale has not been validated in a pregnant population and it tends to provide high false-positive results based on its validation on during the postpartum period. ${ }^{28}{ }^{29}$ Furthermore, the EPDS-3A is a subscale of the EPDS. The standard cut-off point for the EPDS excluding the items of the EPDS-3A has not been established. While the use of a single scale may overestimate the presence of anxiety and/or depression, being able to identify combined anxiety and depression group using a single scale is advantageous as it facilitates for intervention design. While we examined the association between anxiety and/ or depression and PTB analysing the influence of several potential confounders, other confounders such as antidepressant use, other psychiatric conditions and medical risk factors that may influence the associations were not considered since they were not available in the study's data sources. Similarly, we were not able to separate out spontaneous and iatrogenic PTB in the model - the association might be stronger for spontaneous PTB. Overall, replication of this study addressing these limitations may further the understanding on risk factors and preventive strategies of PTB.
We defined neighbourhoods using the smallest area (ie, DA) where people living in the smallest area are more likely to be similar for the outcomes, used multilevel analysis that accounts for area-level variation, and adjusted for individual level variables, an appropriate analytical approach for multilevel data. However, it is difficult to interpret the influence of neighbourhood SES using areabased variables, where women living in the same area share the same value for the variable. Individuals who live in the same area may also experience different contextual influences from many other areal units, and the timing and duration in which individuals experienced these contextual influences is also uncertain.

\section{CONCLUSIONS}

Our study found that the presence of both prenatal anxiety and depression increases the likelihood of PTB and the effect of this combination is stronger for women living in low SES neighbourhoods compared to women living in high SES neighbourhoods. The finding may help to inform development of intervention strategies (such as timely screening and management of anxiety and depression) that focus on the most deprived neighbourhood. Furthermore, future research that examines the influence of severity of anxiety and depression on risk of PTB may further the understanding on risk factors and preventive strategies of PTB.

\section{Author affiliations}

${ }^{1}$ Department of Community Health Sciences, University of Calgary, Calgary, Alberta, Canada

${ }^{2}$ Applied Research and Evaluation- Primary Health Care, Alberta Health Services, Calgary, Alberta, Canada

${ }^{3}$ School of Nursing, Faculty of Health, York University, Calgary, Alberta, Canada ${ }^{4}$ Department of Pediatrics, University of Calgary, Calgary, Alberta, Canada

${ }^{5}$ Faculty of Nursing, University of Calgary, Calgary, Alberta, Canada

${ }^{6}$ Deprtment of Psychiatry, University of Calgary, Calgary, Alberta, Canada

${ }^{7}$ Department of Obstetrics and Gynecology, University of Calgary, Calgary, Alberta, Canada

${ }^{8}$ Department of Medicine, University of Calgary, Calgary, Alberta, Canada

Acknowledgements KA was awarded the Vanier Canada Graduate Scholarship and the Alberta Innovates Graduate Studentship Award. Amy Metcalfe is supported by a Canadian Institutes of Health Research New Investigator Award. We acknowledge the All Our Families and the Alberta Pregnancy Outcomes and Nutrition cohort study teams for providing permission to use their data. We acknowledge SAGE (Secondary Analysis to Generate Evidence), the secure data repository developed by PolicyWise for Children and Families, which houses these datasets, for providing access to these datasets.

Contributors KA involved in the conception and design of the study. KA is also responsible for conducting the analysis, interpreting the data and drafting the manuscript. AM provided overall supervision to Kamala in conducting this study and contributed to conception and study design, interpretation of data, provided intellectual content and revisions to manuscript. SP, TW, ABP, SP, ST, NL and GG were involved in the conception and design of the study and provided interpretation and intellectual content to subsequent drafts of the manuscript. All authors read and approved the final draft.

Funding KA was awarded the Vanier Canada Graduate Scholarship (Award code: 201611CGV-3 82 013-2 67 341) by the Canadian Institutes of Health Research and the Alberta Innovates Graduate Studentship Award (Award code: 201611CGV-3 82 013-2 67341 ) by the Alberta Innovates to conduct this study. 
Disclaimer The funding agencies have no role in study design, data access, analysis and interpretation; manuscript writing and in the decision to submit the article for publication.

Competing interests None declared.

Patient consent for publication Not required.

Ethics approval Ethics approval for this study was obtained from the Conjoint Health Research Ethics Board at the University of Calgary (REB16-2548_REN1). This study used secondary data and all the data were anonymised; therefore, did not require informed consent.

Provenance and peer review Not commissioned; externally peer reviewed.

Data availability statement Data may be obtained from a third party and are not publicly available. Additional data such as statistical codes, supplementary tables and technical appendix are available upon request (by emailing Kamala Adhikari: kamala.adhikaridahal@ucalgary.ca)

Open access This is an open access article distributed in accordance with the Creative Commons Attribution Non Commercial (CC BY-NC 4.0) license, which permits others to distribute, remix, adapt, build upon this work non-commercially, and license their derivative works on different terms, provided the original work is properly cited, appropriate credit is given, any changes made indicated, and the use is non-commercial. See: http://creativecommons.org/licenses/by-nc/4.0/.

\section{ORCID iD}

Kamala Adhikari http://orcid.org/0000-0003-2872-9496

\section{REFERENCES}

1 Blencowe H, Cousens S, Oestergaard MZ, et al. National, regional, and worldwide estimates of preterm birth rates in the year 2010 with time trends since 1990 for selected countries: a systematic analysis and implications. Lancet 2012;379:2162-72.

2 Liu L, Johnson HL, Cousens S, et al. Global, regional, and national causes of child mortality: an updated systematic analysis for 2010 with time trends since 2000. Lancet 2012;379:2151-61.

3 Johnston KM, Gooch K, Korol E, et al. The economic burden of prematurity in Canada. BMC Pediatr 2014;14:93.

4 Blencowe $\mathrm{H}$, Cousens S, Chou D, et al. Born too soon: the global epidemiology of 15 million preterm births. Reprod Health 2013;10:S2.

5 Ward RM, Beachy JC. Neonatal complications following preterm birth. Bjog 2003;110:8-16.

6 Canadian Institute for health information $(\mathrm{CIHI})$. CIHI snapshot: inpatient hospitalizations, surgeries, newborns and childbirth indicators. Available: www.cihi.ca/free_products/cad_hospitalization and_childbirth_snapshot_2015-2016_en.pdf

7 Ding X-X, Wu Y-L, Xu S-J, et al. Maternal anxiety during pregnancy and adverse birth outcomes: a systematic review and meta-analysis of prospective cohort studies. J Affect Disord 2014;159:103-10.

8 Grote NK, Bridge JA, Gavin AR, et al. A meta-analysis of depression during pregnancy and the risk of preterm birth, low birth weight, and intrauterine growth restriction. Arch Gen Psychiatry 2010;67:1012-24.

9 Staneva A, Bogossian F, Pritchard M, et al. The effects of maternal depression, anxiety, and perceived stress during pregnancy on preterm birth: a systematic review. Women Birth 2015;28:179-93.

10 Rose MS, Pana G, Premji S. Prenatal maternal anxiety as a risk factor for preterm birth and the effects of heterogeneity on this relationship: a systematic review and meta-analysis. Biomed Res Int 2016;2016:1-18.

11 Alder J, Fink N, Bitzer J, et al. Depression and anxiety during pregnancy: a risk factor for obstetric, fetal and neonatal outcome? A critical review of the literature. J Matern Fetal Neonatal Med 2007;20:189-209.

12 Misri S, Swift E. Generalized anxiety disorder and major depressive disorder in pregnant and postpartum women: maternal quality of life and treatment outcomes. J Obstet Gynaecol Can 2015;37:798-803.

13 Wenzel A, Haugen EN, Jackson LC, et al. Anxiety symptoms and disorders at eight weeks postpartum. J Anxiety Disord 2005;19:295-311.
14 Field T, Diego M, Hernandez-Reif M, et al. Comorbid depression and anxiety effects on pregnancy and neonatal outcome. Infant Behav Dev 2010;33:23-9.

15 Yang S, Kestens Y, Dahhou M, et al. Neighborhood deprivation and maternal psychological distress during pregnancy: a multilevel analysis. Matern Child Health J 2015;19:1142-51.

16 Kawachi I, Berkman LF. Neighborhood and health. New York: Oxford University Press Inc, 2003.

17 Diez Roux AV, Mair C. Neighborhoods and health. Ann N Y Acad Sci 2010;1186:125-45.

18 Lynch JW, Kaplan GA, Factors S. In: Karachi I and Berkman Lf, social epidemiology. New York: Oxford University Press, 2000.

19 Dunkel Schetter C. Psychological science on pregnancy: stress processes, biopsychosocial models, and emerging research issues. Annu Rev Psychol 2011;62:531-58.

20 Kaplan BJ, Giesbrecht GF, Leung BMY, et al. The Alberta pregnancy outcomes and nutrition (APrON) cohort study: rationale and methods. Matern Child Nutr 2014;10:44-60.

21 Leung BMY, McDonald SW, Kaplan BJ, et al. Comparison of sample characteristics in two pregnancy cohorts: community-based versus population-based recruitment methods. BMC Med Res Methodol 2013;13:149.

22 Roberts GBD. Analyses based on combining similar information from multiple surveys. Section on Survey Research Methods Joint Statistical Meetings 2009:2138-47.

23 Cox JL, Holden JM, Sagovsky R. Detection of postnatal depression. development of the 10-item Edinburgh postnatal depression scale. Br J Psychiatry 1987;150:782-6.

24 Rubertsson C, Börjesson K, Berglund A, et al. The Swedish validation of Edinburgh postnatal depression scale (EPDS) during pregnancy. Nord J Psychiatry 2011;65:414-8.

25 Beck CT, Gable RK. Comparative analysis of the performance of the postpartum depression screening scale with two other depression instruments. Nurs Res 2001;50:242-50.

26 Boyd RC, Le HN, Somberg R. Review of screening instruments for postpartum depression. Arch Womens Ment Health 2005;8:141-53.

27 Gaynes BN, Gavin N, Meltzer-Brody S, et al. Perinatal depression: prevalence, screening accuracy, and screening outcomes. Evid Rep Technol Assess 2005;119:1-8.

28 Matthey S, Fisher J, Rowe H. Using the Edinburgh postnatal depression scale to screen for anxiety disorders: conceptual and methodological considerations. J Affect Disord 2013;146:224-30.

29 Matthey S. Using the Edinburgh postnatal depression scale to screen for anxiety disorders. Depress Anxiety 2008;25:926-31.

30 Pampalon R, Raymond G. A deprivation index for health and welfare planning in Quebec. Chronic Dis Can 2000;21:104-13.

31 Alberta Health Services. How to use the Pampalon deprivation index in Alberta: research and innovation, Alberta health services, 2016.

32 Canadian Institute for Health Information (CIHI). Reducing gaps in health: a focus on socioeconomic status in urban Canada. Ottawa, Ont: CIHI, 2008.

33 StataCrop. Stata manual release 13. Statistical software. Texas: A Stata Press Publication StataCrop LP College Station, 2013.

34 Sterne JAC, White IR, Carlin JB, et al. Multiple imputation for missing data in epidemiological and clinical research: potential and pitfalls. BMJ 2009;338:b2393.

35 Flynn HA, McBride N, Cely A, et al. Relationship of prenatal depression and comorbidities to infant outcomes. CNS Spectr 2015;20:20-8.

36 Ibanez G, Charles M-A, Forhan A, et al. Depression and anxiety in women during pregnancy and neonatal outcome: data from the EDEN mother-child cohort. Early Hum Dev 2012;88:643-9.

37 Pollack MH. Comorbid anxiety and depression. J Clin Psychiatry 2005;66:22-9.

38 Kessler RC. Stress, social status, and psychological distress. J Health Soc Behav 1979;20:259-72.

39 Seguin L, Potvin L, St-Denis M, et al. Chronic stressors, social support, and depression during pregnancy. Obstet Gynecol 1995;85:583-9.

40 McDonald SW, Lyon AW, Benzies KM, et al. The all our babies pregnancy cohort: design, methods, and participant characteristics. BMC Pregnancy Childbirth 2013;13:S2.

41 Gracie SK, Lyon AW, Kehler HL, et al. All our babies cohort study: recruitment of a cohort to predict women at risk of preterm birth through the examination of gene expression profiles and the environment. BMC Pregnancy Childbirth 2010;10:87. 